\title{
Food allergy competencies of dietitians in the United Kingdom, Australia and United States of America
}

\author{
Kate Maslin ${ }^{1,2^{*}}$, Rosan Meyer ${ }^{3}$, Liane Reeves ${ }^{4}$, Heather Mackenzie ${ }^{1}$, Anne Swain ${ }^{5}$, Wendy Stuart-Smith ${ }^{6}$, \\ Rob Loblay ${ }^{5,6}$, Marion Groetch ${ }^{7}$ and Carina Venter ${ }^{1,2}$
}

\begin{abstract}
Background: A knowledgeable and competent dietitian is an integral part of the food allergy multidisciplinary team, contributing to effective diagnosis and management of food allergic disorders. Little is currently known about the food allergy training needs and preferences of dietitians. The purpose of this paper is to measure and compare self-reported food allergy competencies of dietitians based in the UK, Australia and USA.

Methods: A survey of USA-based paediatric dietitians was developed to measure self-reported proficiency and educational needs in the area of food allergy. The survey was modified slightly and circulated online to paediatric and adult dietitians in the UK and Australia. Descriptive statistics and Pearson correlations are presented.

Results: A total of 797 dietitians completed the questionnaire. Competency in "developing food challenge protocols" and "managing feeding problems" were rated the poorest overall across all three settings. A higher level of competency was significantly positively associated with length of practice as a dietitian, percentage of caseload composed of patients with food allergy and training in food allergy. The most popular topics for further training were food additives, pharmacological reactions and oral allergy syndrome.

Conclusions: There is a need amongst dietitians to increase their knowledge in different aspects of food allergy diagnosis and management, specifically the areas of developing food challenge protocols and management of feeding problems. This study provides valuable information for designing targeted food allergy education for dietitians.
\end{abstract}

Keywords: Competency, Dietitian, Food allergy, Knowledge

\section{Introduction}

The main aim in the management of Food Hypersensitivity (FHS) is to prevent the occurrence of acute and chronic symptoms by avoiding the offending food(s), whilst providing a nutritionally balanced diet [1]. In order to ensure effective management of any type of food allergic disorder, an appropriate dietary assessment and avoidance strategy is required [2]. A knowledgeable and competent food allergy dietitian is uniquely qualified to deliver this [3]. In recent years, five official international

\footnotetext{
* Correspondence: kate.maslin@port.ac.uk

${ }^{1}$ School of Health Sciences \& Social Work, University of Portsmouth, Portsmouth, UK

${ }^{2}$ David Hide Asthma and Allergy Research Centre, Isle of Wight, UK

Full list of author information is available at the end of the article
}

guidelines have been published on the diagnosis and management of food allergies; the World Allergy Organisation (WAO) guidelines on the diagnosis and management of cow's milk allergy [4], the USA National Institute of Allergy and Infectious Disease (NIAID) guidelines on the diagnosis and management of food allergies in adults and children [5], the UK National Institute of Health and Clinical Excellence (NICE) guidelines on the diagnosis of food allergies in children [6], the European Society for Paediatric Gastroenterology, Hepatology and Nutrition guidelines on Cow's Milk Protein Allergy [7] and the Irish Food Allergy Network (IFAN) Paediatric Food allergy guidelines [8]. Although each of these guidelines identifies the

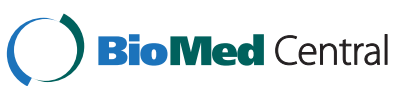

(c) 2014 Maslin et al.; licensee BioMed Central Ltd. This is an Open Access article distributed under the terms of the Creative Commons Attribution License (http://creativecommons.org/licenses/by/4.0), which permits unrestricted use, distribution, and reproduction in any medium, provided the original work is properly credited. The Creative Commons Public Domain Dedication waiver (http://creativecommons.org/publicdomain/zero/1.0/) applies to the data made available in this article, unless otherwise stated. 
importance of a nutrition consultation, only the UK NICE, ESGPHAN and IFAN guidelines recognise that dietitians play a key role in both the diagnosis and management of food allergies.

In practice, the role of the dietitian working in the area of food allergy involves a range of responsibilities, consisting of, but not limited to [9]; taking an allergyfocused diet history and interpretation of skin prick tests, advising on formula choice and complementary feeding including nutrient supplements, allergen avoidance advice including practical advice on substitutes and recipes and monitoring nutritional status. Crucially, the dietitian has a lead role in the planning and design of food challenges for both diagnosis and determination of tolerance. A double blind placebo controlled food challenge remains the gold standard for diagnosis of food allergy [10]. Although in clinical practice, food challenges are typically not double blinded, expertise is required to calculate and translate appropriate doses to acceptable portion sizes. However, a previous survey of dietitians in the USA [11] indicated that despite good knowledge levels in some aspects of food allergy, a significant number of dietitians had no proficiency in developing food challenge protocols. This paper will compare self-reported food allergy competencies of dietitians based in the UK, Australia and USA, by combining previously published data from US -based paediatric dietitians [11] with new data which surveyed both adult and paediatric dietitians based in Australia and the UK.

\section{Methods}

The original survey of USA-based paediatric dietitians undertaken by Groetch et al. [11] was developed by a group of expert health professionals from the Consortium of Food Allergy Research (CoFAR), to measure self-reported proficiency and educational needs and preferences of paediatric dietitians. It was piloted, then distributed online to the Paediatric Nutrition Practice Group of the Academy of Nutrition \& Dietetics. Respondents were asked to rate their knowledge and competency on a four point scale (high, moderate, low and not at all proficient). Permission to use this data as a published resource, in combination with newly collected data, was granted.

For both the UK and Australia, the questionnaire was modified to address local conditions. A five-point scale was used (high, moderate, low, not at all proficient and $\mathrm{N} / \mathrm{A}$ in my practice). The questionnaire used in the UK is shown in Additional file 1: Table S1. The questionnaire used in Australia differed slightly as it had separate questions about Food Allergy (FA) and Food Intolerance (FI), where the term 'food allergy' was solely used for describing IgE mediated food allergy.

\section{Sample}

The distribution of the survey differed between countries. In the UK, a weblink was posted on the British Dietetic Association's (BDA) website, which has approximately 7000 members. The questionnaire was also published once in the BDA magazine and emailed once to dietitians who are members of specialist groups.

In Australia the questionnaire was circulated once via a weekly newsletter to all Dietetic Association of Australia (DAA) members, which has approximately 5000 members. A reminder email was sent three weeks later to the Food Allergy and Intolerance, Gastroenterology and Paediatric and Maternal Health Interest groups.

In the UK, the University of Portsmouth ethics committee was consulted, who advised that specific ethical permission was not required to undertake an online survey. In Australia, ethical approval was obtained from the Research Development Office of the Royal Prince Alfred Hospital, New South Wales.

Descriptive statistics are presented. Percentage responses are calculated per question based on the number of respondents answering the question. All statistical analyses were conducted using SPSS version 20.0 (SPSS, Inc., Chicago, ILL, 2012). One-tailed Pearson correlations were calculated to determine if any factors were associated with higher levels of competency.

\section{Results}

\section{Participant characteristics}

A total of 797 dietitians completed the questionnaire. Demographic characteristics of all participants are shown in Table 1.

A considerable number of participants worked in an outpatient setting (39\%, 42\% and $46 \%$ of UK, Australia and USA-based dietitians respectively). The majority of dietitians based in UK (58.3\%) and Australia (77\%) learnt about FA during their basic dietetic training. However in the USA, the majority of respondents (51.7\%) learnt about allergy after qualifying as a dietitian.

The results of the UK and Australia questionnaires are compared with the results previously published by Groetch et al., [11] in Table 2.

\section{Food Allergy topics with high level of competency}

Topics that were rated as "high" levels of competency are displayed in Figure 1. The USA-based dietitians had the greatest proportion of respondents rating themselves as highly competent for 6 areas (understanding definitions of FA and FI, recognising signs and symptoms, educating patients on avoidance, managing multiple food allergies and managing feeding problems). UK-based dietitians had the greatest proportion of respondents rating themselves highly in 2 areas (understanding diagnosis of 
Table 1 Demographic characteristics of all participants

\begin{tabular}{|c|c|c|c|c|}
\hline \multirow[t]{2}{*}{ Characteristic } & \multirow[t]{2}{*}{ Options } & \multirow{2}{*}{$\begin{array}{c}\text { UK } \\
(n=336) \\
\%\end{array}$} & \multirow{2}{*}{$\begin{array}{c}\text { Australia } \\
(n=150) \\
\%\end{array}$} & \multirow{2}{*}{$\begin{array}{c}\text { USA } \\
(n=311)[11] \\
\%\end{array}$} \\
\hline & & & & \\
\hline \multirow[t]{4}{*}{ Years in practice } & $0-5$ years & 31.7 & 42.0 & 20.6 \\
\hline & 6-10 years & 21.7 & 18.7 & 14.8 \\
\hline & $11-15$ years & 15.5 & 12.0 & 15.1 \\
\hline & $>15$ years & 31.8 & 27.3 & 49.5 \\
\hline \multirow[t]{9}{*}{ Practice settings } & Hospital (outpatient) & 39.0 & 42.0 & 46.0 \\
\hline & Hospital (inpatient)* & $N A^{*}$ & 40.0 & 37.6 \\
\hline & Private practice & 2.7 & 32.0 & 13.2 \\
\hline & Community & 36.0 & 34.0 & - \\
\hline & Industry & 0.0 & 2.0 & - \\
\hline & Food Service & 0.0 & 4.6 & - \\
\hline & Academic & 0.3 & 2.6 & - \\
\hline & Research & 0.9 & 5.3 & - \\
\hline & Other & 21.1 & 4.6 & 28.3 \\
\hline \multirow[t]{2}{*}{ Caseload composed of food allergy patients** } & $<10 \%$ & $31.0^{* *}$ & 66.0 & 57.6 \\
\hline & $>10 \%$ & $69.0^{* *}$ & 34.0 & 42.4 \\
\hline \multirow[t]{3}{*}{ Allergy training } & During dietetic training & 58.3 & 77.0 & 31.0 \\
\hline & Post registration course & 17.0 & 28.0 & 51.9 \\
\hline & Postgraduate course & 5.1 & 3.0 & $N A^{* * *}$ \\
\hline \multirow[t]{4}{*}{ CPD resources currently used ${ }^{* * * *}$} & Academic journals & - & 89.0 & 85.1 \\
\hline & Academic websites & - & 52.7 & 59.3 \\
\hline & Dietetic/advocacy groups & - & 70.1 & 72.0 \\
\hline & Conferences & - & 70.0 & 56.0 \\
\hline
\end{tabular}

$\mathrm{NA}=$ Not Applicable.

*UK questionnaire did not specify inpatient or outpatient.

**The UK respondents were not directly asked the proportion of their caseload comprised of FA patients. These figures relate to respondents who answered "not at all" or "slightly relevant" to the question "How relevant/applicable to your practice were the questions in this survey?".

***USA questionnaire did not list "postgraduate course" as an option.

****UK questionnaire did not ask what CPD resources currently used.

Table 2 Comparison of food allergy knowledge and competencies of dietitians based in the UK, Australia and USA

\begin{tabular}{|c|c|c|c|c|c|c|c|c|c|c|c|c|}
\hline & \multicolumn{3}{|c|}{ High } & \multicolumn{3}{|c|}{ Moderate } & \multicolumn{3}{|c|}{ Low } & \multicolumn{3}{|c|}{ Not at all } \\
\hline & Aus & USA & UK & Aus & USA & UK & Aus & USA & UK & Aus & USA & UK \\
\hline Understand FA & 25 & 57 & 23 & 45 & 41 & 53 & 18 & 2 & 17 & 8 & 0 & 5 \\
\hline Understand FI & 43 & 59 & 22 & 45 & 39 & 54 & 10 & 2 & 18 & 1 & 0 & 4 \\
\hline Understand diagnosis of FA/FI & 18 & 19 & 23 & 41 & 53 & 41 & 30 & 24 & 26 & 8 & 4 & 6 \\
\hline Recognise signs and symptoms of $\mathrm{FA} / \mathrm{FI}$ & 25 & 29 & 23 & 50 & 58 & 48 & 20 & 12 & 22 & 3 & 2 & 4 \\
\hline Develop Food Challenge protocols & 13 & 8 & 8 & 35 & 35 & 25 & 35 & 38 & 32 & 13 & 19 & 23 \\
\hline Educate patients on avoidance & 30 & 42 & 33 & 39 & 46 & 42 & 25 & 12 & 18 & 3 & 1 & 4 \\
\hline Develop elimination diet & 18 & 14 & 21 & 23 & 40 & 25 & 22 & 31 & 12 & 18 & 15 & 10 \\
\hline Manage Multiple FA & 17 & 28 & 21 & 17 & 49 & 23 & 26 & 20 & 13 & 19 & 3 & 12 \\
\hline Manage Feeding problems & 13 & 17 & 9 & 19 & 39 & 25 & 26 & 33 & 19 & 23 & 10 & 13 \\
\hline
\end{tabular}




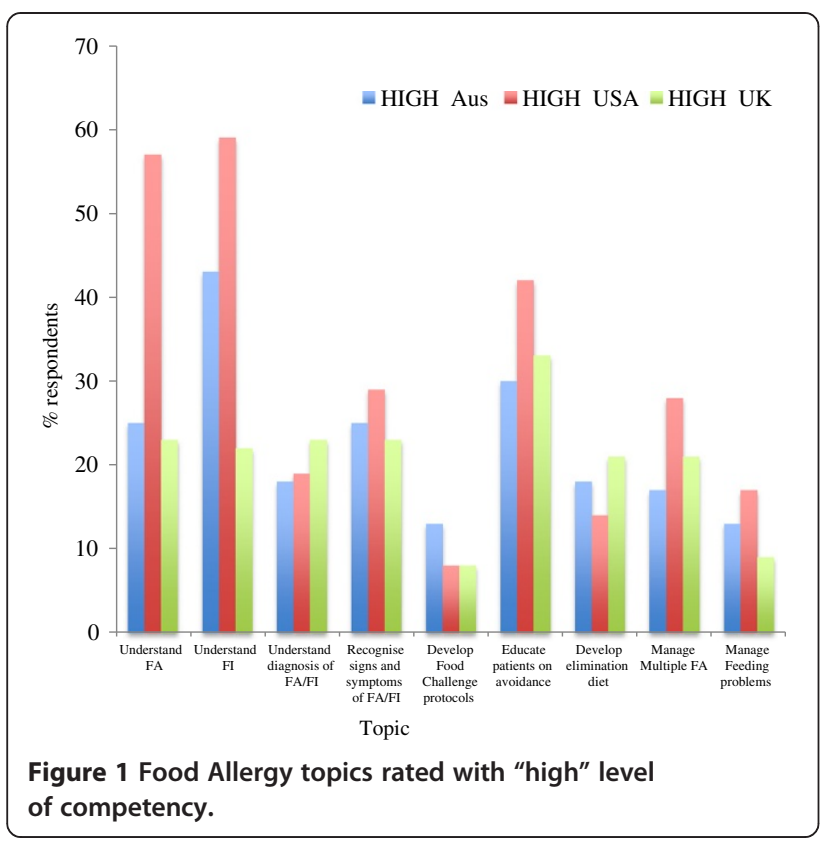

FA \& FI and developing an elimination diet). Australiabased dietitians had the greatest proportion of respondents rating themselves highly for one area (developing food challenge protocols), however this was only $13 \%$ of respondents.

\section{Food Allergy topics with low levels of competency}

The competencies that were rated the poorest overall across all three countries were developing food challenge protocols and managing feeding problems, with $19 \%$ and $13 \%$ of all respondents respectively rating themselves as "not at all proficient".

However Pearson correlations calculated for the UK and Australia data indicate that higher competency in the areas of food challenge and managing feeding problems were significantly positively associated with length of practice as a dietitian, percentage of caseload composed of food allergy patients and training in food allergy. The strongest correlation existed between higher competency in managing feeding problems and\% of caseload composed of allergy patients $(\mathrm{r}=0.50, p<0.01$ in UK and $\mathrm{r}=0.517, p<0.01$ in Australia). There was no correlation between competency in these two areas and setting of workplace. Correlation coefficients are displayed in Table 3.

\section{Further training needed}

Respondents in the UK and Australia were asked which specific FA topics they would like further training in. Results are shown in Table 4. Of note, the most popular topics were: reactions to food additives $(67 \%$ and $73 \%$ in the UK and Australia respectively), pharmacological reactions $(66 \%$ and $70 \%$ in the UK and Australia respectively) and oral allergy syndrome (62\% and $68 \%$ in the UK and Australia respectively).

\section{Educational resources needed}

When asked what resources they would be "very likely" or "likely" to use to improve their knowledge of FA; a handbook, basic course and web-based programme were the most popular choices. Results are displayed in Figure 2.

\section{Discussion}

This study set out to compare self-reported food allergy knowledge and competencies of dietitians in the UK, USA and Australia, by combining previously published data from USA -based paediatric dietitians [11] with new data from Australia and the UK. Overall we found

Table 3 Correlation between competency in food challenge protocols and feeding problems and participant characteristics

\begin{tabular}{|c|c|c|c|c|}
\hline & \multicolumn{2}{|c|}{ UK } & \multicolumn{2}{|c|}{ Australia } \\
\hline & \multicolumn{2}{|c|}{$(n=336)$} & \multicolumn{2}{|c|}{$(n=150)$} \\
\hline & Food challenge protocols & Feeding problems & Food challenge protocols & Feeding problems \\
\hline \multirow[t]{2}{*}{ Years of practice } & $r=0.12$ & $r=0.246$ & $r=0.204$ & $r=0.26$ \\
\hline & $p<0.05$ & $p<0.01$ & $p<0.01$ & $p<0.01$ \\
\hline \multirow[t]{2}{*}{ Setting of practice } & $r=0.08$ & $r=0.02$ & $r=0.019$ & $r=0.04$ \\
\hline & $p=0.71$ & $p=0.32$ & $p=0.40$ & $p=0.29$ \\
\hline \multirow[t]{2}{*}{ Caseload of allergy patients } & $r=0.32$ & $r=0.50$ & $r=0.487$ & $r=0.517$ \\
\hline & $p<0.01$ & $\mathrm{p}<0.01$ & $\mathrm{p}<0.01$ & $\mathrm{p}<0.01$ \\
\hline \multirow[t]{2}{*}{ Specialist allergy conference } & $r=0.423$ & $r=0.478$ & $r=0.256$ & $r=0.339$ \\
\hline & $\mathrm{p}<0.01$ & $\mathrm{p}<0.01$ & $p<0.01$ & $p<0.01$ \\
\hline \multirow[t]{2}{*}{ FA education/ workshop } & $r=0.264$ & $r=0.413$ & $r=0.416$ & $r=0.382$ \\
\hline & $p<0.01$ & $\mathrm{p}<0.01$ & $\mathrm{p}<0.01$ & $p<0.01$ \\
\hline
\end{tabular}

Strong positive correlations $(r>0.4)$ are in bold. 
Table 4 Food allergy and intolerance training needs of UK and Australia-based dietitians

\begin{tabular}{lcc}
\hline Topic & UK (\%) & Australia (\%) \\
& $\mathbf{n = 3 3 6}$ & $\mathbf{n = 1 5 0}$ \\
\hline Reactions to food additives & 67 & 73 \\
Pharmacological reactions (e.g. salicylates) & 66 & 70 \\
Oral Allergy Syndrome & 62 & 68 \\
Management of Irritable Bowel Syndrome & 53 & 48 \\
Cereal allergy & 47 & 52 \\
Cows' milk protein allergy & 39 & 50 \\
Soy allergy & 46 & 39 \\
Nut and seed allergy & 45 & 42 \\
Fish/shellfish allergy & 43 & 38 \\
Egg allergy & 37 & 38 \\
Coeliac disease & 21 & 29 \\
Lactose intolerance & 34 & 14 \\
\hline
\end{tabular}

evidence of suboptimal levels of knowledge and competency in several key food allergy aspects across all three countries.

The original questionnaire used by Groetch et al. [11] was developed to identify the self-reported food allergy proficiency and education needs of paediatric dietitians in the United States. Similarly, the later two questionnaires were administered to both adult and paediatric dietitians in Australia and the UK to establish a baseline of knowledge and competencies in order to advance the education and training of dietitians in the area of food allergy. This is in acknowledgement of the pivotal role dietitians play in the diagnosis and management of both adults and children with food allergy.

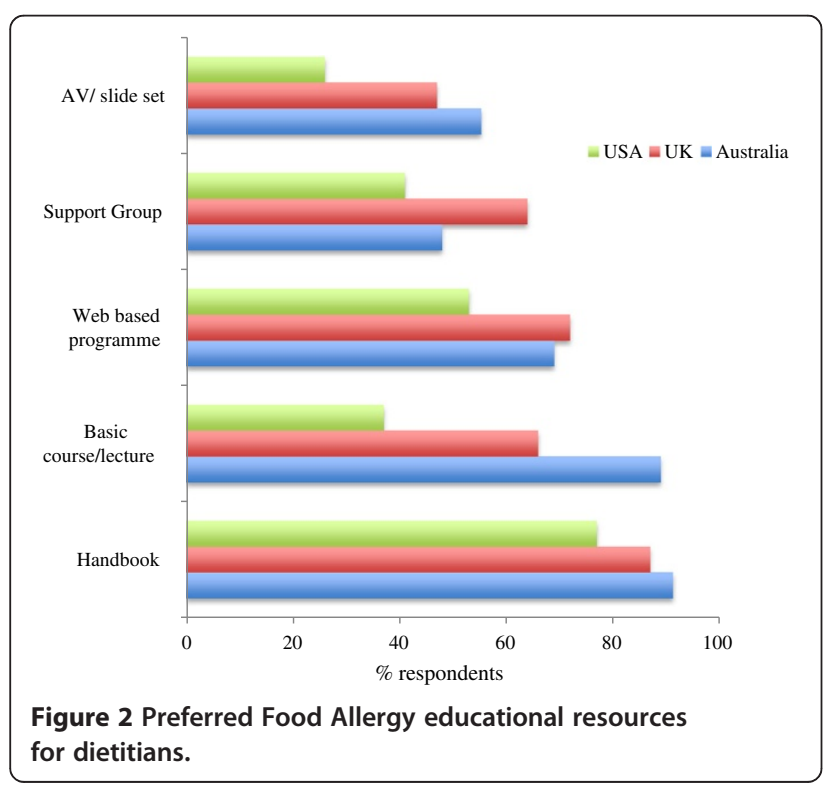

Although the questionnaires were made available to dietitians working in all clinical specialities and those not working in food allergy were encouraged to respond, only $5 \%$ of the UK-based respondents reported the questionnaire was 'not at all relevant' to their practice, indicating that knowledge of food allergy is broadly relevant to the vast majority of UK-based dietitians, even if they are working in another clinical speciality. More than $50 \%$ of the Australia-based respondents were working with paediatric or adult food allergy patients at the time of the survey, again emphasising how food allergy pervades across dietetic practice. Similarly, $90 \%$ of the USAbased sample worked with food allergy patients, however this could be skewed by the fact that only paediatric dietitians were recruited in the USA and it is well known that food allergy is more prevalent in children that adults [12].

The differences seen between countries could be explained by differences in dietetic training internationally. A greater percentage of Australia and UK based dietitians than USA based dietitians, reported to have learnt about FA during basic dietetic training. Attempts have been made to standardise the undergraduate and postgraduate training of nutrition and dietetic professionals across the world $[13,14]$. However, a report from The International Confederation of Dietetic Associations (2008) [14] highlighted the heterogeneity of dietetic training and practice in different countries in terms of level of basic education, practical experience, competency standards and scope of practice. The importance of establishing internationalism in dietetic training in order to produce practitioners that are competent to manage emerging diseases has previously been raised [15].

A key trend emerging from these three questionnaires is the discrepancy in knowledge across different aspects of FA diagnosis and management. The public confusion that exists between perceived and actual food allergy may be contributing to this problem [16]. Although some aspects of FA management (e.g. educating patients about food avoidance, recognising signs and symptoms, understanding definitions) were well rated, others such as developing food challenges were rated poorly across all three cohorts. This was particularly the case in the UK-based cohort, where half of respondents who reported that the questionnaire was "moderately or very" relevant to their practice, rated their competency level to be "low" or "not at all proficient". This is extremely critical to the progression of allergy services in the UK, in order to ensure that patients are correctly diagnosed and timely monitored for determining tolerance to food allergens [17]. Without the availability of trained health professionals to design and implement food challenges, it is likely that patients may be incorrectly diagnosed 
and placed on an exclusion diet unnecessarily. Indeed a lack of allergy services providing appropriately designed hospital-based food challenges may mean that unsafe home reintroduction challenges will be advocated, thus putting patients at risk. Reassuringly, there was a strong positive correlation between attendence at a specialist FA conference or education/workshop and competency in the area of food challenges.

Our findings are in agreement with research that has been conducted in other health professional groups across the world. A study of doctors $(n=1317)$ in the UK regarding knowledge of cow's milk allergy also demonstrated significant learning gaps about basic concepts [18]. Although the emphasis of the research was primary prevention of food allergy, rather than diagnosis and management, a Brazilian study of paediatricians, paediatric gastroenterologists, allergists and nutritionists $(\mathrm{n}=$ 520), also found gaps in knowledge across all professional groups [19]. In the USA, approximately $60 \%$ of primary care and paediatric physicians answered knowledge-based items correctly in the Chicago Food Allergy Research Survey [20]. However, only 24\% were aware that oral food challenges could be used to diagnose food allergy; less than $30 \%$ felt confident to interpret biochemical results to diagnose food allergy and only $22 \%$ felt their medical training prepared them adequately to care for patients with food allergy. Finally in a South African study of dietitians and medical practitioners [21] $(n=660), 98 \%$ of respondents believed they needed more training in food allergy management at undergraduate and postgraduate level.

In our participants, although the majority of respondents used academic journals as a means to maintain $\mathrm{CPD}$ and some had attended food allergy conference or courses, the low number of respondents who had completed postgraduate training in food allergy should be emphasised. Further training on food additives and pharmacological reactions was requested by the UK and Australia based respondents, perhaps influenced by the adult dietitians included in both samples. In terms of resources that would be most useful, similar results were seen across the three cohorts, with a handbook, basic course or web-based programme proving most popular.

The use of online training courses has been demonstrated to be effective in increasing postgraduate knowledge in other areas of dietetics such as childhood obesity [22] and infant feeding [23]. Massive Open Online Courses (MOOCs) offer a convenient method to provide distance learning education to dietitians and health professionals internationally, with proven good completion rates and increases in competency [23]. Walsh's study [18] provides evidence of an improvement in UK doctors' knowledge of milk allergy using an online training course. Whether this success can be replicated, using a standardized approach across different countries, given the aforementioned differences in undergraduate training, remains to be seen.

There are several limitations to this study. Firstly the response rate of the questionnaires in the UK and Australia was between $3-5 \%$, therefore it is possible that a response bias exists, where those who are interested in food allergy are most likely to participate. Each of the questionnaires was worded slightly differently, in order to adapt the content to local practices (e.g. the questionnaire used in Australia discriminated between FA and FI, the USA and UK based questionnaire did not). The UK questionnaire did not specifically ask the proportion of the caseload composed of allergy patients; instead the question of "how relevant is this questionnaire to your practice" was used as a surrogate to discriminate between those who did and did not work with patients with food allergy. In order to be more inclusive, the UK and Australia questionnaire recruited dietitians who work with both adult and paediatric patients, unlike the original USA based study, which was only aimed at paediatric dietitians. This means the results are not directly comparable. A further limitation is that all the questions were self-rated and therefore subjective. Strengths of the study design are that it included a large number of dietitians (total 797 respondents), with varied years of experience, working in different settings across three different continents.

\section{Conclusions}

There is a need amongst dietitians to increase their knowledge in different aspects of food allergy management, specifically the areas of developing food challenge protocols and management of feeding problems. Dietitians in the UK and Australia identified pharmacological reactions and food additives as the areas of greatest training need and rated a handbook, basic food allergy course or web-based programme as the most preferred methods of learning. Data from these three cohorts provides valuable information for designing food allergy education material for dietitians, which can then be adapted according to country specific needs.

\section{Additional file}

Additional file 1: Table S1. Questionnaire used in the United Kingdom.

\section{Competing interests}

The authors declare that they have no competing interests. No external funding was received to undertake this research.

Authors' contributions

KM conducted the data analysis and wrote the manuscript. RM developed the UK questionnaire and assisted with data analysis. LR developed the UK questionnaire and undertook data collection in the UK. HM designed the online questionnaire for Australia-based participants. AS, WSS and RL were 
involved in design and data collection of Australia based participants. MG designed the original questionnaire, collected and analysed the USA data. CV was responsible for the overall concept, design of the UK questionnaire, initial data analysis and revision of manuscript. All authors reviewed the manuscript and approved the final version.

\section{Acknowledgements}

The authors wish to acknowledge the respondents of the questionnaire, the British Dietetic Association, the Dietetic Association of Australia and the Academy of Nutrition and Dietetics.

\section{Author details}

'School of Health Sciences \& Social Work, University of Portsmouth, Portsmouth, UK. ${ }^{2}$ David Hide Asthma and Allergy Research Centre, Isle of Wight, UK. ${ }^{3}$ Department of Gastroenterology, Great Ormond Street Hospital for Sick Children, London, UK. ${ }^{4}$ Oxford Health NHS Foundation Trust, Oxford, UK. ${ }^{5}$ The Allergy Unit at Royal Prince Alfred Hospital, Sydney, Australia. ${ }^{6}$ University of Sydney, Sydney, Australia. ${ }^{7}$ Icahn School of Medicine at Mount Sinai, New York, USA.

Received: 20 June 2014 Accepted: 1 October 2014

Published: 14 November 2014

\section{References}

1. Venter C, Laitinen $K$, Vlieg-Boerstra B: Nutritional aspects in diagnosis and management of food hypersensitivity-the dietitians role. J Allergy 2012, 2012:269376.

2. Groetch M, Nowak-Wegrzyn A: Practical approach to nutrition and dietary intervention in pediatric food allergy. Pediatr Allergy Immu 2013, 24:212-221.

3. Fox AT, Lloyd K, Arkwright PD, Bhattachary D, Brown T, Chetcuti P, East M, Gaventa J, King R, Martinez A, Meyer R, Parikh A, Perkin M, Shah N, Tuthill D, Walsh J, Waddell L, Warner J, Science and Research Department, Royal College of Paediatrics and Child Health: The RCPCH care pathway for food allergy in children: an evidence and consensus based national approach. Arch Dis Child 2011, 96:i25-i29.

4. Fiocchi A, Brozek J, Schünemann H, Bahna SL, von Berg A, Beyer K, Bozzola M, Bradsher J, Compalati E, Ebisawa M, Guzmán MA, Li H, Heine RG, Keith P, Lack G, Landi M, Martelli A, Rancé F, Sampson H, Stein A, Terracciano L, Vieths S, World Allergy Organization (WAO) Special Committee on Food Allergy: World Allergy Organization (WAO) Diagnosis and Rationale for Action against Cow's Milk Allergy (DRACMA) guidelines. Pediat Allergy Immu 2010, 21:S1-S25.

5. Boyce JA, Assa'ad A, Burks AW, Jones SM, Sampson HA, Wood RA, Plaut M, Cooper SF, Fenton MJ, Arshad SH, Bahna SL, Beck LA, Byrd-Bredbenner C, Camargo CA Jr, Eichenfield L, Furuta GT, Hanifin JM, Jones C, Kraft M, Levy BD, Lieberman P, Luccioli S, McCall KM, Schneider LC, Simon RA, Simons FE, Teach SJ, Yawn BP, Schwaninger JM, NIAID-Sponsored Expert Panel: Guidelines for the diagnosis and management of food allergy in the United States: summary of the NIAID-sponsored expert panel report. J Allergy Clin. Immunol 2010, 126:1105-1118.

6. National Institute for Health and Clinical Excellence: Food allergy in children and young people. Diagnosis and assessment of food allergy in children and young people in primary care and community settings. In NICE Clinical Guidelines CG116. London: National Institute for Health and Clinical Excellence; 2011.

7. Koletzko S, Niggemann B, Arato A, Dias JA, Heuschkel R, Husby S, Mearin ML, Papadopoulou A, Ruemmele FM, Staiano A, Schäppi MG, Vandenplas Y, European Society of Pediatric Gastroenterology, Hepatology, and Nutrition: Diagnostic approach and management of cow's-milk protein allergy in infants and children: ESPGHAN GI Committee practical guidelines. J Pediatr Gastroenterol Nutr 2012, 55:221-229.

8. Irish Food allergy Network: Paediatric Food allergy: Guidelines for diagnosis and management in Primary Care. Dublin: Irish Food Allergy Network; 2012

9. Venter C, Brown T, Shah N, Walsh J, Fox AT: Diagnosis and management of non-IgE-mediated cow's milk allergy in infancy - a UK primary care practical guide. Clin Transl Allergy 2013, 3:23.

10. Sampson HA, Gerth van Wijk R, Bindslev-Jensen C, Sicherer S, Teuber SS, Berks AW, Dubois AE, Beyer K, Eigenmann PA, Spergel JM, Werfel T, Chinchilli VM: Standardizing double blind, placebo-controlled oral food challenges: American Academy of Allergy, Asthma \& Immunology-European Academy of Allergy and Clinical Immunology PRACTALL consensus report. J Allergy Clin Immunol 2012, 130:1260-1274.

11. Groetch ME, Christie L, Vargas L, Jones SM, Sicherer SH: Food Allergy Educational needs of Pediatric Dietitians: A Survey by the Consortium of Food Allergy Research. J. Nutr Educ Behav 2010, 42:259-264.

12. Rona RJ, Keil T, Summers C, Gislason D, Zuidmeer L, Sodergren E, Sigurdardottir ST, Lindner T, Goldhahn K, Dahlstrom J, McBride D, Madsen C: The prevalence of food allergy: A Meta Analysis. J Allergy Clin Immunol 2007, 120:638-646.

13. Lawrence MA, Galal O, Margetts BM, Yngve A: Building global alliances for public health nutrition training. Nutr Rev 2009, 67:566-S68.

14. International Confederation of Dietetic Associations: Dietitians around the World. In Their education and their work 2012. International Confederation of Dietetic Associations; 2014. http://www.internationaldietetics.org/InternationalStandards/ICDA-Reports.aspx.

15. Truby H: Internationalism in dietetic education and practise. J Hum Nutr 2010, 23:203-204

16. Beker $L$, Koerner $C B$ : Dietitians face the challenge of food allergies. J Am Diet Assoc 2010, 100:13-14.

17. Royal College of Physicians: Allergy services: still not meeting the unmet need. London: RCP; 2010.

18. Walsh J: What do Doctors know? Cow's Milk Allergy and Lactose Intolerance. In Abstract presented at BSPGHAN annual meeting January. London; 2014. https://bspghan.org.uk/annual-meeting.

19. Ribeiro CC, Leite Speridiao Pda G, De Morais MB: Knowledge and practice of physicians and nutritionists regarding the prevention of food allergy. Clin Nutr 2013, 32:624-629.

20. Gupta RS, Springston EE, Kin JS, Smith B, Kim JS, Pongracic JA, Wang X, Holl J: Food allergy knowledge, attitudes and beliefs of primary care physicians. Pediatrics 2010, 125:126-132.

21. Stear GIJ, Potter PC, Labadarios D, Motala: Management of food allergies in children in South Africa - determining aspects of the knowledge and practices of dietitians and medical practitioners. Curr Allergy Clin Im 2011, 24:145-155

22. Stark CM, Graham-Keifer ML, Devine CM, Dollahite JS, Olson CM: Online course increases nutrition professionals' knowledge, skills and selfefficacy in using an ecological approach to prevent childhood obesity. J Nutr Educ Behav 2011, 43:316-322.

23. Stark CM, Pope J: Massive open online courses: how registered dietitians use MOOCs for nutrition education. J Acad Nutr Diet 2014, 114:1147-1155.

doi:10.1186/2045-7022-4-37

Cite this article as: Maslin et al:: Food allergy competencies of dietitians in the United Kingdom, Australia and United States of America. Clinical and Translational Allergy 2014 4:37.

\section{Submit your next manuscript to BioMed Central and take full advantage of:}

- Convenient online submission

- Thorough peer review

- No space constraints or color figure charges

- Immediate publication on acceptance

- Inclusion in PubMed, CAS, Scopus and Google Scholar

- Research which is freely available for redistribution

Submit your manuscript at www.biomedcentral.com/submit
C Biomed Central 